\title{
Delhi's dumps are "public health time bombs"
}

$\mathrm{W}$ hen the sun is still rising from behind it, the mountain of garbage - plastic bags, construction rubble, medical waste, animal carcasses - seems beautiful.

"The first time I saw it, I said, 'Wow, is that the Aravalli Range?'” says my translator, journalist Raksha Kumar.

The Okhla landfill is one of three major dump sites in New Delhi, which accumulates 8000 tons of municipal solid waste a day, according to the city government website. The city's engorged landfills are also sitting on prime land, explains Mahesh Babu, managing director of a private consulting company on waste solutions with IL\&FS Environmental Infrastructure and Services Ltd.

The solution to Delhi's at-capacity landfills, according to the government and private waste management companies lies in a controversial United Nations-supported plan to incinerate waste to produce energy. Delhi now has one operating waste-to-energy (WtE) plant, which has drastically reduced the number of trucks destined for the Okhla landfill; two more are planned.

But Delhi's 40 000-plus "rag pickers," those who scavenge waste for recyclable and reusable materials, are less enthused. The first incinerator has already eliminated hundreds of jobs, according to surveys conducted by the Chintan Environmental Research and Action Group.

Mumtaz puts a face to those numbers. She lives in a cardboard house on a strip of dirt between the Okhla landfill and a six-lane highway with her four children, in a slum that depends partly on the landfill's bounty. With Mumtaz looking after her three young children, Ambiya, her 11-year-old daughter, is the breadwinner. The girl works 11-hour days, six days a week, climbing the garbage mountain with her eyes peeled. If she finds iron, she can make 200 rupees (about \$4) a day; if not, other types of scrap net her only 40 rupees.

"She falls ill quite a lot," Mumtaz says in Hindi. Ambiya has monthly bouts of vomiting, dysentery and fever. "It's hard labour."

Dunu Roy, director of Hazards Centre, a community-centred nongovernmental organization, explains waste pickers are often cut by needles or metal, for example, and "these cuts get infected quite quickly because of the nature of the wastes they deal with." Chemicals, including insecticides and pesticides are another danger. "They affect the eyes, the lungs and the skin."

Life didn't used to be quite as hard for Ambiya. Half a year ago, she was going to school, and earning as much in three hours of "rag picking" as she earns now in 12 hours, plus she could find wood for cooking fires.

That was before the launch of the first WtE incinerator, part of a private-public

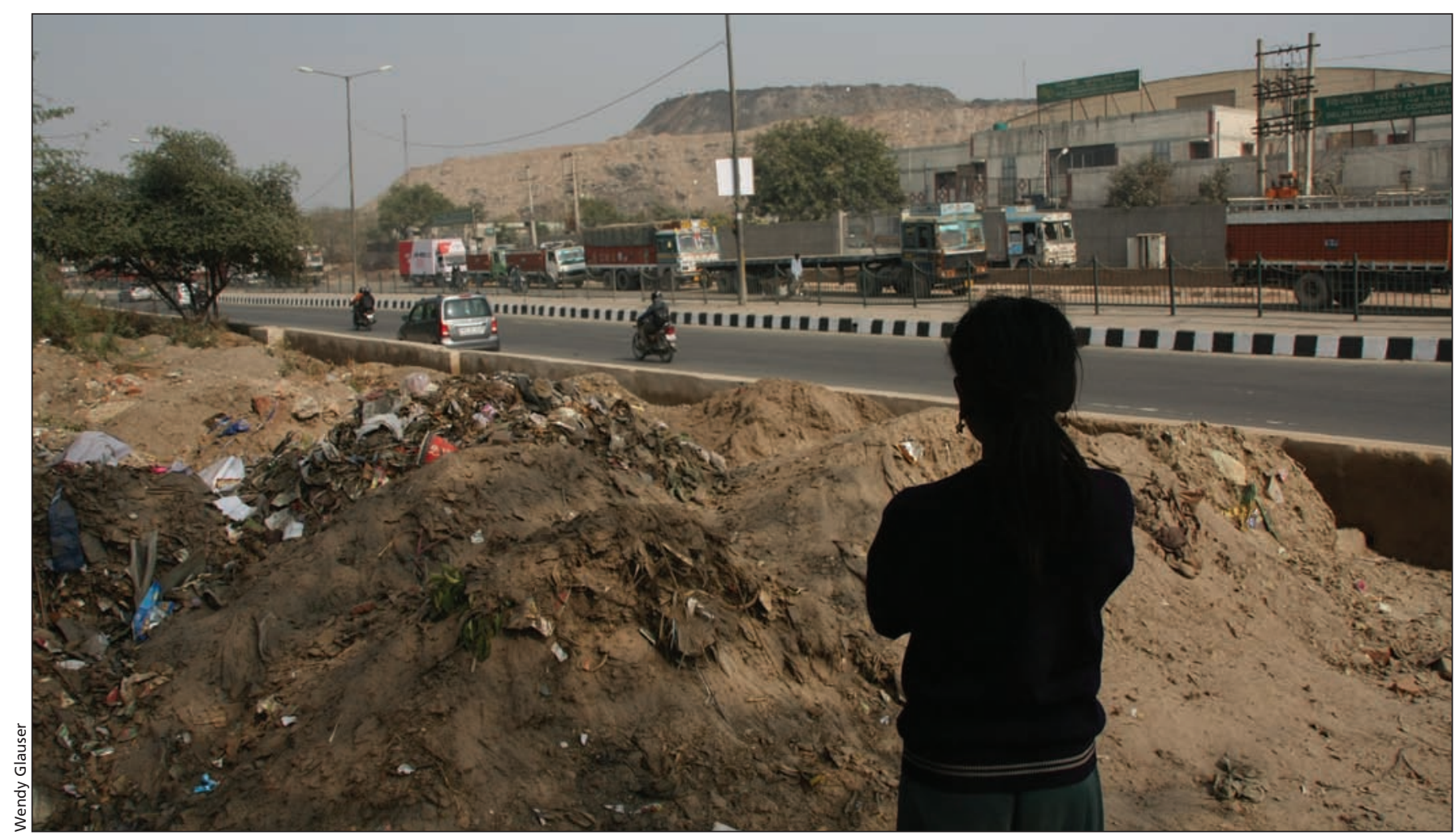

Ambiya, 11, looks across the highway to her workplace, a 32-acre landfill where she scavenges for plastics and metals. 
partnership between the Delhi government and India-owned Jindal Group. The initiative is partly funded by the Clean Development Mechanism (CDM) of the Kyoto protocol, which pays a set amount for every ton of greenhouse gases an approved project is able to reduce from baseline measurements. In the case of the WtE plant, the 10 to 16 megawatts of energy produced offsets carbon created from coal or gas-derived energy.

However, local residents and watchdog groups are concerned about pollutants not measured under the CDM, including cancer-causing dioxins and heavy metals. Babu claims nonburnables are separated out and not incinerated. He says that suction technology means the plant releases only steam in the air.

But residents say they smell burning plastic. And in December, the media reported on a temporary release of ashy dust from the plant that landed on cars and houses and was described as "toxic snow."

"It was soapy, it would lather," says resident Naintra Devraj who lives in one of the densely built, multistorey apartments located a few hundred metres from the plant. According to Devraj, when the wind blows from the plant, the smell is so bad that "people who visit ask us how we can stand it."

Last year, the environment minister informed parliament that the Delhi Pollution Control Committee found levels of particulate matter have exceeded the standard on four out of ten tests.

Gopal Krishna, head of Toxics Watch Alliance, which has filed numerous complaints about the WtE plant, says the fact that the plant is still running after exceeding pollutant standards is just one in a long string of violations. "There is collusion between the ruling party, the opposition party and the company," he says.

Krishna is most concerned about dioxins, which the government is not equipped to measure.

Officials in the environment ministry didn't respond to interview requests over a three-week period.

David Abbass, information officer at the United Nations Framework Convention on Climate Change secretariat, says all CDM projects must follow national environmental standards, but it's up to local governments to ensure such standards are enforced.

"If [local environmental protections] are not good, should the CDM not operate? It's an interesting conversation," says Abbass, one that he calls an "academic" question and outside of his purview, which is limited to explaining the CDM's operations.

The development of the burning plants stems from the increasingly colossal trash footprint of status-seeking and timepressed Delhiites, says Roy. "More and more consumer goods are coming on to the market," he says. "Food is now being packaged whereas before it wasn't. There are Styrofoam, plastic and aluminum containers everywhere."

Both Roy and Krishna argue the government should abandon WtE plants and instead employ waste pickers in municipal recycling and compost programs after providing them with protective gear. But, explains Roy, such programs are expensive and the World Bank impels India's government to cut down on waste removal costs.

"The choice of waste technology is not driven by social or economic needs, but by profit motivation," says Roy. "And it's being supported by a host of international institutions, including the UN." — Wendy Glauser, New Delhi, India

CMAJ 2013. DOI:10.1503/cmaj.109-4423 